\title{
Management of Pneumocystis Jirovecii pneumonia in HIV infected patients: current options, challenges and future directions
}

This article was published in the following Dove Press journal:

HIVIAIDS - Research and Palliative Care

23 June 2010

Number of times this article has been viewed

\author{
Jose G Castro' \\ Maya Morrison-Bryant ${ }^{2}$ \\ 'Division of Infectious Diseases, \\ University of Miami Miller School \\ of Medicine, Miami, Florida, USA; \\ ${ }^{2}$ Jackson Memorial Hospital/University \\ of Miami Infectious Diseases \\ Fellowship Program, Miami, Florida, \\ USA
}

\begin{abstract}
The discovery of the Human Immunodeficiency Virus (HIV) was led by the merge of clustered cases of Pneumocystis jirovecii Pneumonia (PCP) in otherwise healthy people in the early 80 's. ${ }^{1,2}$ In the face of sophisticated treatment now available for HIV infection, life expectancy approaches normal limits. It has dramatically changed the natural course of HIV from a nearly fatal infection to a chronic disease. ${ }^{3-5}$ However, PCP still remains a relatively common presentation of uncontrolled HIV. Despite the knowledge and advances gained in the prevention and management of PCP infection, it continues to have high morbidity and mortality rates. Trimethoprim-sulfamethoxazole (TMP-SMZ) remains as the recommended first-line treatment. Alternatives include pentamidine, dapsone plus trimethoprim, clindamycin administered with primaquine, and atovaquone. For optimal management, clinicians need to be familiar with the advantages and disadvantages of the available drugs. The parameters used to classify severity of infection are also important, as it is well known that the adjunctive use of steroids in moderate to severe cases have been shown to significantly improve outcome. Evolving management practices, such as the successful institution of early antiretroviral therapy, may further enhance overall survival rates.
\end{abstract}

Keywords: HIV, Pneumocystis Jirovecii, PCP, TMP-SMZ

\section{Introduction}

Pneumocystis in humans is caused by $P$. jirovecii, as opposed to $P$. carinii, the latter being one of the two Pneumocystis species found only in rats. ${ }^{6}$ The organism was classified as a protozoan nearly 100 years ago. ${ }^{7,8}$ In 1988 it was identified as a fungus based on DNA analysis. ${ }^{9,10}$ P. jirovecii is a fungus that has maintained its importance as a pathogen because of its frequent presentation as pneumonia in patients with $\mathrm{T}$ cell mediated immunodeficiency.

Examples of those at risk include persons with a primary or hereditary immunodeficiency, persons on antineoplastic therapy, immunosuppressive drugs, glucocorticoids, those with hematological malignancies (leukemia, lymphoma, multiple myeloma), and of course HIV infection. Three decades into the HIV/AIDS epidemic it remains as one of the most prevalent opportunistic infections. It is still a common AIDS defining illness leading to the diagnosis of HIV infection and bringing patients to medical attention.

$P$. jirovecii has a worldwide distribution and humans appear to be a reservoir for this fungus. The modes of transmission and acquisition are not completely understood. It was previously thought that $P$. jirovecii did not infect the immunologically normal host. However, recent studies in immunocompetent animals have shown that $P$. jirovecii 
produces a typical pattern of infection, transmission and resolution. ${ }^{11}$ In addition, PCP was traditionally believed to arise from reactivation of latent infection. This was probably because of the evidence of exposure and likely asymptomatic infection early in life and active disease occurring several years later. However, no evidence for latency has ever been demonstrated. Mouse and rat models of PCP have shown that latency does not develop after infection, which suggests that PCP results from new infection rather than reactivation of latent infection. ${ }^{12}$ The latter is supported by data showing that distinct strains are responsible for each episode in patients who develop multiple episodes of PCP. ${ }^{13}$

$P$. jirovecii is acquired by inhalation. Once in the alveoli, it adheres to type I cells, and the subsequent interaction of $P$. jirovecii with the alveolar epithelium is considered critical to the infectious process. ${ }^{14}$ A significant pulmonary inflammatory response ensues which more potently contributes to lung injury than the direct effect of the organism during Pneumocystis pneumonia. The importance of the immune response was initially demonstrated in an experiment in which mice with severe combined immunodeficiency were infected with PCP, and following infusion with functional lymphocytes, a rapid deterioration and even death was seen. ${ }^{15}$ Subsequent studies showed that the restoration of immune function in the presence of PCP, resulted in a rapid increase of proinflammatory cytokines, chemokines and cellular infiltrate in the lungs of mice, as the adopted immune system began to function and clear infection. ${ }^{16}$ In these studies, mice with similar burden of infection, but without restoration of immune function, were remarkably normal in terms of their cytokine response and physiologic parameters. It has been proposed that when a balanced $\mathrm{CD}^{+}$and $\mathrm{CD}^{+} \mathrm{T}$-cell response occurs, as in the normal host, the infection will lead to mild inflammation that will destroy $P$. jirovecii and with relative preservation of lung function. However, when $\mathrm{CD}^{+} \mathrm{T}$ cells initiate the inflammatory response in the abscense of sufficient $\mathrm{CD} 4^{+} \mathrm{T}$ cells to control the infection, a hyper-inflammatory response follows causing severe lung damage without reducing organism burden. ${ }^{17}$

A detailed discussion of the clinical presentation and diagnostic procedures available for PCP is beyond the scope of this review, but widely available. ${ }^{18-20}$ Briefly, the clinical presentation can vary, though most patients are usually ill for two to three weeks. Progressive dyspnea is characteristic, but dry cough, tachycardia, tachypnea, hypoxia, and low-grade fever are also common manifestations. Lung auscultation in comparison to symptoms is usually unremarkable. Arterial blood gas analysis demonstrates an increased alveolar-arterial gradient and respiratory alkalosis. Oxygen desaturation of $\geq 5 \%$ with exercise is a reliable and quick test. ${ }^{21}$ Early in the disease course the chest radiography may be normal, but will classically show fine, bilateral, diffuse infiltrates beginning in the perihilar regions. Other presentations include cystic formation, unilateral infiltrates, cavitary lesions, nodular densities, pleural effusion, pneumothorax, and pneumomediastinum (Figures 1-6). ${ }^{22}$ High resolution computer assisted tomography (CAT) scans are more sensitive than chest radiography in the diagnosis of $\mathrm{PCP}^{23}$

Definitive diagnosis is based on identification of the organism on histopathology. Sputum induction with hypertonic saline has a diagnostic yield ranging from 50 to $90 \%$ and specificity approaching $100 \% .{ }^{24}$ Fiberoptic bronchoscopy with bronchoalveolar lavage has $>90 \%$ sensitivity and $100 \%$ specificity. Immunofluorescent staining of bronchial specimens is the most sensitive and specific diagnostic test readily available. ${ }^{25}$

Polymerase chain reaction testing of induced sputum or bronchoalveolar lavage can also identify and quantitate Pneumocystis. Several studies have suggested that PCR can be a sensitive and specific diagnostic test on these samples, as well as oro-pharyngeal washes, but no commercial PCR test is broadly available at this time. ${ }^{26}$ For example some of these newer PCR diagnostic tests include assays to amplify the human Pneumocystis mithocondrial large subunit rRNA, and the internal transcribed spacer region genes. However,

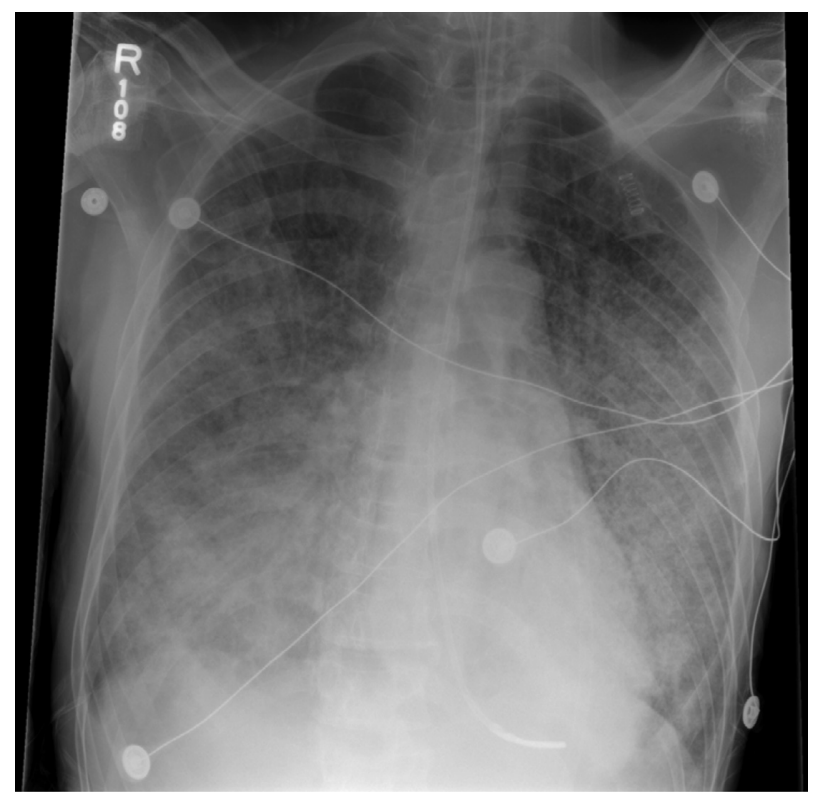

Figure I Chest radiograph showing bilateral diffuse interstitial infiltrates and airspace opacities of Pneumocystis pneumonia. 


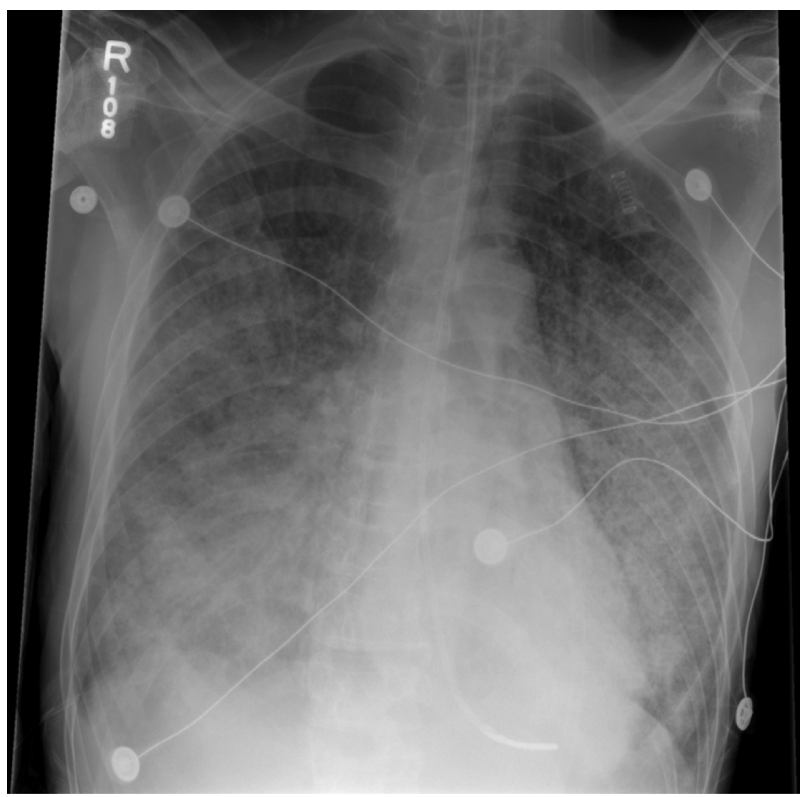

Figure 2 Case 2, Chest radiograph showing bilateral diffuse interstitial infiltrates and airspace opacities of Pneumocystis pneumonia.

the availability of an accurate serologic test would be a major advance in the diagnosis of PCP. Recent reports describe potential candidates such as detection of the serum (1-3) beta-D-glucan. ${ }^{27,28}$

\section{Treatment}

Untreated PCP is almost always fatal. In patients without HIV infection, response to treatment should begin in 4 to

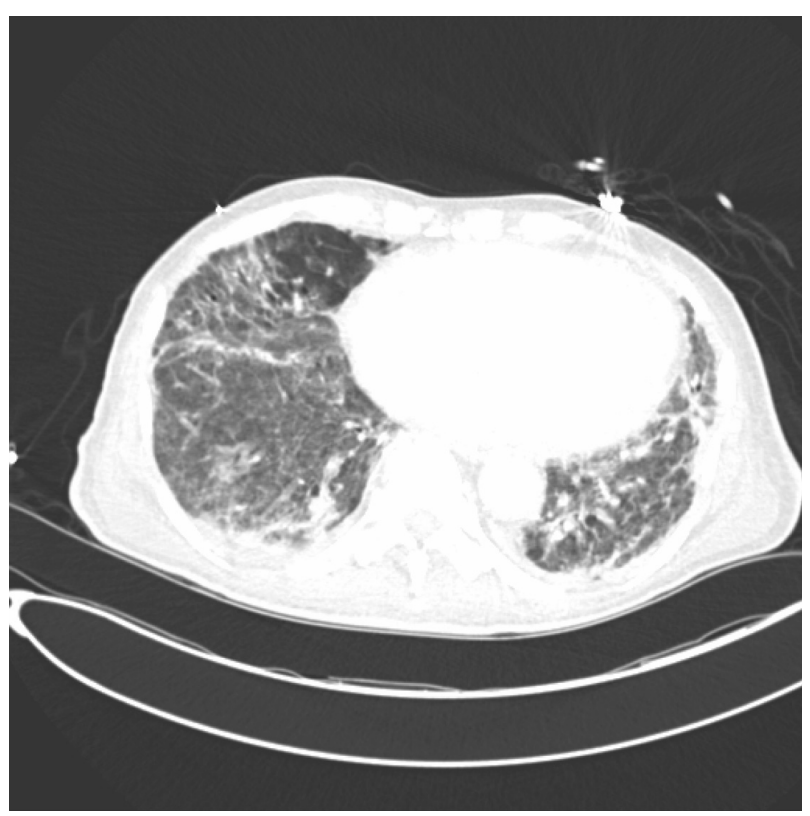

Figure 3 One slice from CAT scan of the lungs showing patchy bilateral areas of ground glass infiltrates and multiple pneumatoceles taken from a patient with Pneumocystis.

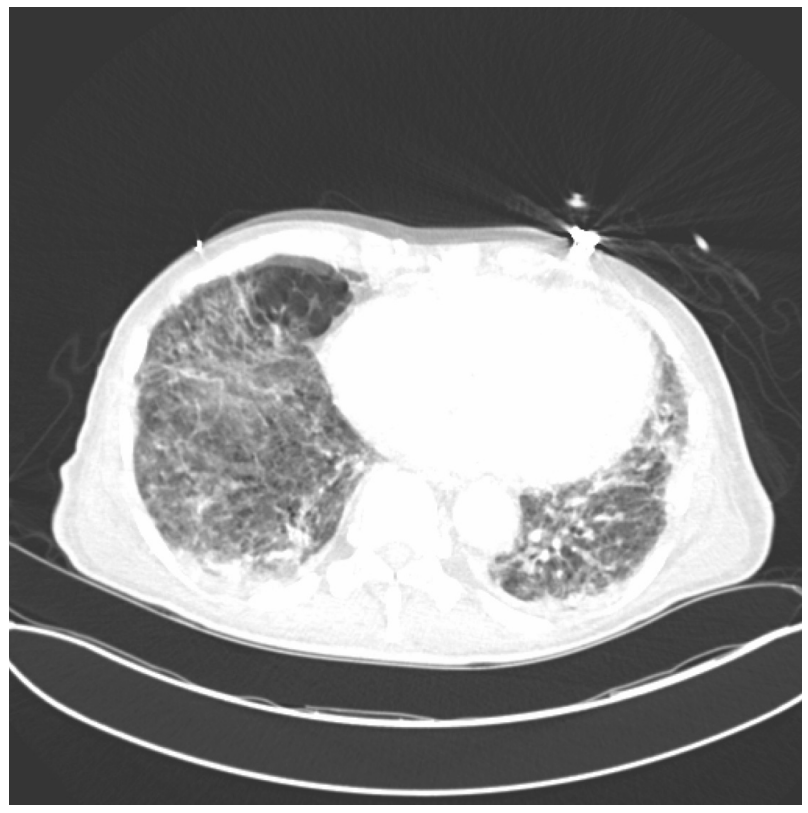

Figure 4 One slice from CAT scan of the lungs showing patchy bilateral areas of ground glass infiltrates and multiple pneumatoceles taken from a patient with Pneumocystis.

5 days. In patients infected with HIV, the treatment response typically takes longer but should occur within the first 8 days. It is not uncommon to observe clinical deterioration in the first 24 hours of the initiation of therapy, especially in moderate or severe cases. If no response occurs within the expected time, an alternative diagnosis should be sought, including concurrent infections; ${ }^{29-31}$ otherwise, an appropriate alternative regimen should be used.

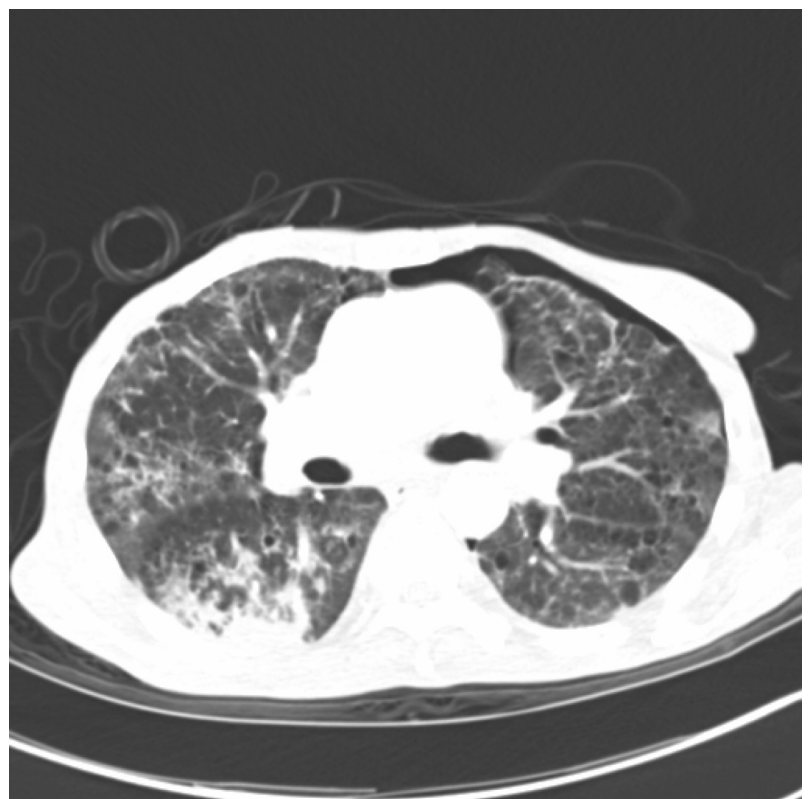

Figure 5 One slice of CAT scan of the lungs showing widespread emphysematous and cystic changes along with multifocal interstitial infiltrates in a severe case of Pneumocystis pneumonia. 


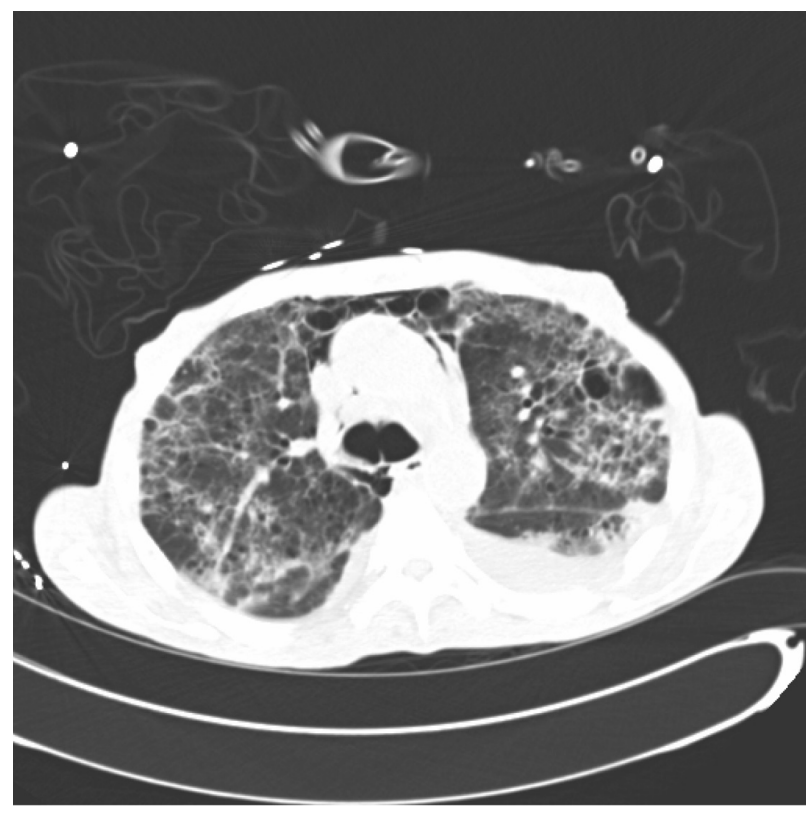

Figure 6 One slice of CAT scan of the lungs showing widespread emphysematous and cystic changes along with multifocal interstitial infiltrates in a severe case of Pneumocystis pneumonia.

The length of treatment is 21 days in HIV-infected patients and 14 days in non-HIV infected individuals. It is common practice to extend therapy if there is a delay in the resolution of signs and symptoms. A longer duration of treatment in HIVinfected individuals is often needed due to the larger burden of organisms and the slower response to therapy.

The dosages of these medications must be adjusted for renal or hepatic impairment. Treatment options, including the type of medications, need for in-patient care and respiratory support will be decided by the treating team and will depend primarily on the degree of illness at diagnosis (Table 1). In general, the parenteral route is preferred for administering antibiotics to patients who present with moderate or severe disease or in those with gastrointestinal upset. The recommended and alternative schemas of treatment are summarized in Table 2.

\section{Antibiotics}

These are the mainstay of treatment for PCP. A summary of the dose, contra-indications and common side effects are presented in Table 3.

Table I Severity of PCP

\begin{tabular}{ll}
\hline Degree & A-a gradient* \\
\hline Mild & $<35 \mathrm{mmHg}$ \\
Moderate & $35-45 \mathrm{mmHg}$ \\
Severe* & $>45 \mathrm{mmHg}$ \\
\hline
\end{tabular}

*A-a gradient: alveolar-arterial gradient.

* Severe disease also defined by an Oxygen pressure of $70 \mathrm{mmHg}$ taken at room air.
Table 2 PCP treatment regimens

\section{Preferred regimens}

- Trimethoprim (TMP)

$15-20 \mathrm{mg} / \mathrm{kg} /$ day + sulfamethoxazole $75-100 \mathrm{mg} / \mathrm{kg} /$ day PO or IV for

$2 \mathrm{I}$ days in 3 to 4 divided doses.

- Adjunctive corticosteroids

In moderate to severe disease should receive corticosteroids (prednisone $40 \mathrm{mg}$ PO bid $\times 5$ days, then $40 \mathrm{mg}$ qd ( 5 days, then $20 \mathrm{mg} /$ day to completion of treatment) starting as early as possible. IV methylprednisolone

\section{Alternative regimens}

- TMP $15 \mathrm{mg} / \mathrm{kg} /$ day PO + dapsone $100 \mathrm{mg} /$ day PO $\times 21$ days.

- Pentamidine 3-4 mg/kg/day IV infused over $>60 \mathrm{~min} \times 21$ days.

- Clindamycin 600-900 mg IV q6h-8h or 300-450 mp PO $\mathrm{q} 6 \mathrm{~h}+$ primaquine $15-30 \mathrm{mg} /$ day base $\mathrm{PO} \times 21$ days.

- Atovaquone $750 \mathrm{mg}$ suspension PO bid with meal $\times 21$ days.

\section{Trimethoprim-sulfamethoxazole (TMP-SMX)}

Trimethoprim-sulfamethoxazole (TMP-SMX) is the drug of choice for pneumocystis. TMP-SMX is made up of two antimicrobial agents that act synergistically against a wide variety of bacteria. Although trimethoprim has been combined with other sulfonamides, TMP-SMX is by far the most widely used. TMP and SMX are individually weak bactericidal agents, but when given together, they become highly bactericidal against many bacteria. Maximum inhibition of most susceptible bacteria occurs when the TMP-SMX concentration ratio is $1: 20$. The drug combination is prepared in a higher fixed ratio of 1:5; however, peak serum concentrations of 1:20 are still achieved by both oral and intravenous therapy because of the wider volume of distribution of TMP.

This regimen has been widely recommended as first line therapy for the management of HIV-related Pneumocystis opportunistic infections. ${ }^{32}$ It has been shown in numerous studies to be more or equally effective as pentamidine which was the drug of choice for the treatment of PCP before the advent of the HIV/AIDS epidemic. TMP-SMX has the advantage of a comparatively favorable toxicity profile and has gained wide acceptance due to its long track record and easy availability. ${ }^{33-36}$

A prospective randomized non-crossover trial comparing these two regimens, helped to clarify the results of the more common complex trials that allowed for frequent changes in regimen, due to a lack of response or because of adverse effects. This study reported that $86 \%$ of patients treated with TMP-SMX survived and were without respiratory support at completion of treatment compared to $61 \%$ in the pentamidine group, $95 \% \mathrm{CI}$ for the difference in response, $5 \%$ to $45 \%$; $P=0.03 .^{37}$ 
Table 3 Drugs for treatment of PCP

\begin{tabular}{|c|c|c|c|}
\hline Regimen & Dosage & Contraindications & Common adverse effects \\
\hline $\begin{array}{l}\text { TMP-SMS } \\
\text { (Bactrim, Septra) }\end{array}$ & $5 \mathrm{mg} / \mathrm{kg}$ of TMP every $8 \mathrm{hrs}$ & $\begin{array}{l}\text { hypersensitivity, megaloblastic anemia } \\
\text { due to folate deficiency }\end{array}$ & $\begin{array}{l}\text { skin reaction (mild rash to anaphylaxis), drug } \\
\text { fever, bone marrow suppression, nausea } \\
\text { and vomiting, diarrhea, pancreatitis, nephritis, } \\
\text { and hyperkalemia }\end{array}$ \\
\hline $\begin{array}{l}\text { Dapsone } \\
\text { (Avlosulfon) }\end{array}$ & 100 mg daily & $\begin{array}{l}\text { hypersensitivity, G-6-PD } \\
\text { deficiency }\end{array}$ & $\begin{array}{l}\text { fever, rash, hemolytic anemia, nausea, vomiting, } \\
\text { methemoglobinemia, hepatitis, } \\
\text { aplastic anemia }\end{array}$ \\
\hline $\begin{array}{l}\text { Clindamycin } \\
\text { (Cleocin) }\end{array}$ & $900 \mathrm{mg}$ IV q $8 \mathrm{~h}$ & $\begin{array}{l}\text { hypersensitivity, regional Enteritis, } \\
\text { ulcerative colitis, Hepatic impairment, } \\
\text { antibiotic associated colitis. }\end{array}$ & $\begin{array}{l}\text { diarrhea, nausea, vomiting, rash, } \\
\text { clostridium, difficile associated colitis }\end{array}$ \\
\hline $\begin{array}{l}\text { Atovaquone } \\
\text { (Mepron) }\end{array}$ & 750 mg PO BID & hypersensitivity & $\begin{array}{l}\text { rash, GI intolerance, diarrhea, headache, fever, } \\
\text { insomnia }\end{array}$ \\
\hline $\begin{array}{l}\text { Pentamidine } \\
\text { Pentam-300 }\end{array}$ & $4 \mathrm{mg} / \mathrm{kg} / \mathrm{d} \mathrm{IV} / \mathrm{IM}$ & hypersensitivity & $\begin{array}{l}\text { nausea, cardiac arrthytmias, hyperkalemia, } \\
\text { nephrotoxicity, hypo-hyperglycemia, } \\
\text { hyper-hypo tension, Hepatic dysfunction, } \\
\text { leucopenia, thrombocytopenia }\end{array}$ \\
\hline $\begin{array}{l}\text { Trimetrexate }{ }^{*} \\
\text { (Neutrexin) }\end{array}$ & $45 \mathrm{mg} / \mathrm{m} 2 \mathrm{IV}$ qd & $\begin{array}{l}\text { hypersensitivity, severe } \\
\text { myelosuppression }\end{array}$ & $\begin{array}{l}\text { myelosuppression, increases in serum } \\
\text { aminotransferase levels, anemia, fever, } \\
\text { rash/pruritus, and increased alkaline } \\
\text { phosphatase or serum creatinine levels }\end{array}$ \\
\hline Primaquine & $15-30 \mathrm{mg}$ PO & hypersensitivity, G-6-PD deficiency & $\begin{array}{l}\text { hemolytic anemia, methemoglobinemia, } \\
\text { leucopenia, nausea, vomiting, epigastric pain }\end{array}$ \\
\hline
\end{tabular}

"No longer available in the US.

The mechanism of action of this combined drug regimen involves the sequential inhibiton of folate biosynthesis by the organism. Sulfamethoxazole competitively inhibits dihydropteroate synthase (DHPS) which catalyses the condensation of $p$-aminobenzoic acid and 6-hydroxymethyl-7,8dihydropterin pyrophosphate to form dihydropteroate. ${ }^{38}$ Trimethoprim inhibits microbial dihydrofolate reductase, and by this action inhibits purine synthesis and thereby prevents deoxyribonucleic acid production. These sequential inhibitors in folic acid synthesis likely results in a synergistic killing effect of microbes. ${ }^{39,40}$

TMP-SMX absorption is not affected by food or other medications and bioavailability is approximately $85 \%$ for both compounds. TMP-SMX is available in oral and parenteral forms. Peak serum levels of TMP-SMX after administration of a double-strength tablet are 1 to 2 microgram $/ \mathrm{mL}$ and 25 to $60 \mathrm{microgram} / \mathrm{mL}$, respectively. Peak concentrations are attained within 2 to 4 hours with oral therapy and within 1 to 2 hours with parenteral therapy. The concentrations achieved after intravenous administration of TMP-SMX are equivalent to two DS tablets and are 3.5 microgram $/ \mathrm{mL}$ and $47.3 \mathrm{microgram} / \mathrm{mL}$ respectively. Intravenous therapy is preferred when absorption is unreliable. TMP-SMX is widely distributed in the body but tissue concentrations are generally less than serum concentrations. TMP is more lipophilic than SMX (apparent volume of distribution 100 to $120 \mathrm{~L}$ and 12 to $18 \mathrm{~L}$ respectively), resulting in ratios of
$1: 2$ to $1: 10$ in tissues compared to $1: 20$ in the extracellular fluid. CSF penetration of TMP-SMX is generally good, with TMP concentrations ranging from $20 \%$ to $60 \%$ of serum values and SMX concentrations ranging from $12 \%$ to $50 \%$ of serum values. The recommended dose for the treatment of PCP is 15 to $20 \mathrm{mg} / \mathrm{kg}$ of TMP per day and 75 to $100 \mathrm{mg} /$ $\mathrm{kg}$ of SMX per day, divided in three or four doses.

TMP-SMX is generally well tolerated in non-HIVinfected patients. Adverse reactions occur in approximately $6 \%$ to $8 \%$ of such individuals. In comparison, the adverse reaction rate is as high as $25 \%$ to $50 \%$ in HIV-infected patients. In the latter group, treatment limiting toxicities occur in one third of cases. ${ }^{41}$

Reported toxicities include skin reactions (ranging from mild rash to anaphylaxis), drug fever, bone marrow suppression, nausea and vomiting, diarrhea, pancreatitis, nephritis, metabolic acidosis, and hyperkalemia. Hyperkalemia is due to the blockade of the collecting tubule sodium channel by trimethoprim (an action similar to that induced by the potassium-sparing diuretic amiloride). Hyperkalemia is most commonly seen in HIV-infected patients who are treated with high doses, but normal doses can also produce a modest elevation in the plasma potassium concentration in non-HIV-infected subjects.

Nephrotoxicity associated with TMP-SMX is uncommon; however, TMP is known to decrease the tubular secretion of creatinine. This has led to increases in serum creatinine 
through interference with certain assays that is not reflective of a true reduction in glomerular filtration rate.

TMP-SMX desensitization could potentially allow for its use in those with hypersensitivity reactions. However, there is no established regimen proven to be safe in such patients. Mild adverse reactions can be managed with supportive care and discontinuation of the drug. Attempts at desensitization with increasing doses of bactrim can be done in mild cases but, this should never be attempted in those whose adverse event involves severe rash with mucosal involvement, or anaphylactic type reactions. With the wide use and success of other therapeutic treatments available, clinical circumstances may dictate when desensitization procedures are warranted.

Therapeutic failure with TMP-SMX occurs in up to $20 \%$ of cases and cannot be solely attributable to gene mutations. There are no standardized culture systems for $P$. jirovecii and therefore data on drug resistance is unavailable. ${ }^{42}$ TMP-SMX resistance is mainly due to point mutations in dihydropteroate synthase, but, the extent of resistance conferred by these mutations is unknown without in vitro susceptibility tests. ${ }^{42}$ Mutations in the DHPS gene increases with exposure to sulfa drugs and in chemoprophylaxis. ${ }^{42}$ Though the presence of these mutations were independently associated with a significant increase in 3-month mortality in one study, ${ }^{43}$ they have not been shown to invariably result in treatment failure. Additionally, successful outcome with TMP-SMX in these instances has been well documented. ${ }^{44}$

In patients who are allergic to or intolerant of sulfonamides, there are several alternatives for mild to moderate disease (that is usually with an alveolar-arterial oxygen gradient $\leq 45 \mathrm{mmHg}$ ).

\section{Dapsone}

Dapsone is a synthetic sulfone rapidly and almost completely absorbed from the gastrointestinal tract. Peak dapsone plasma concentrations are reached within 2 to 8 hours after administration. The mean half-life of elimination is about 20 to 30 hours. Twenty-four hours after oral ingestion of $100 \mathrm{mg}$, plasma concentrations range from 0.4 to $1.2 \mu \mathrm{g} / \mathrm{ml}$. A dose of $100 \mathrm{mg}$ per day produces steady-state plasma concentrations of free dapsone of 2 to $6 \mu \mathrm{mol} / \mathrm{L}$.

About $70 \%$ of the drug is bound to plasma protein. Dapsone is distributed throughout total body water and is present in all tissues. However, it tends to be retained in the skin, muscle and especially in the liver and kidney. Traces of the drug are present in these organs up to 3 weeks after cessation of therapy. Following absorption from the gastrointestinal tract, dapsone is transported through the portal circulation to the liver, where it is metabolized by both $\mathrm{N}$-acetylation and N-hydroxylation. Dapsone toxicity, in particular methemoglobin formation, is generally thought to be initiated by $\mathrm{N}$-oxidation, resulting in the formation of a hydroxylamine metabolite by cytochrome P450.

Dapsone acts against bacteria and protozoa in the same way as sulphonamides, by inhibiting the synthesis of dihydrofolic acid through competition with para-amino-benzoate for the active site of dihydropteroate synthetase. Its efficacy is similar to TMP-SMX in mild to moderately severe disease with less toxicity. ${ }^{45}$ Dapsone $100 \mathrm{mg}$ daily plus trimethoprim $15 \mathrm{mg} / \mathrm{kg}$ daily is given by mouth in 3 divided doses.

Dapsone therapy may cause a variety of adverse effects, which may be categorized as pharmacologic, dose-dependent, allergic, or idiosyncratic reactions. The most frequent and well-documented pharmacologic reactions are the hematological side-effects, such as methemoglobinemia, hemolysis (in patients who have glucose 6 phosphate dehydrogenase (G6PD) deficiency) and anemia. Methemoglobinemia occurs to some extent in all patients receiving dapsone and becomes less pronounced as treatment is continued due to an adaptive increase in the activity of nicotinamide adenine dinucleotide (NADH) dependent reductase in the erythrocytes. Methemoglobin levels of below 20\% are not usually associated with symptoms. Dyspnea, nausea and tachycardia usually occur at levels of $30 \%$ or above, while lethargy, stupor and deteriorating consciousness occur as methemoglobin levels approach 55\%. Levels of 70\% are usually fatal. Once methemoglobinemia is suspected, evaluation with a complete blood count to identify anemia or thrombocytopenia, a blood smear for Heinz body formation, G6PD assay, arterial blood gas and methemoglobin level should be performed to confirm the diagnosis.

Case reports of dapsone-induced methemoglobinemia in the literature describe the improvement of mild symptoms with discontinuation of therapy and supportive measures. ${ }^{46}$ While more symptomatic presentations are treated with methylene blue and activated charcoal to prevent further gastrointestinal absorption. Methylene blue acts as a co-factor for the alternative pathway of the nicotinamide adenine dinucleotide phosphate (NADPH) system, to convert methaemoglobin to haemoglobin. ${ }^{47}$ However, methylene blue should not be administered in the presence of G6PD deficiency, where low levels of NADPH exist making it ineffective. In this situation methylene blue may induce hemolytic anemia, and blood transfusions are likely to be more useful here, and in cases refractory to treatment with methylene blue. ${ }^{48}$ Treatment of PCP should resume with alternative options for PCP. 
Other side effects include fever, nausea, vomiting, peripheral motor weakness, dose-unrelated granulocytopenia, aplastic anemia, and cutaneous reactions such as the sulfone syndrome.

\section{Clindamycin}

Clindamycin is another comparable alternative to TMP-SMX in terms of therapeutic success and safety. ${ }^{49}$ The dose is $300-450 \mathrm{mg}$ orally four times a day (or 600-900 mg IV every 6 to 8 hours) plus primaquine $15-30 \mathrm{mg}$ of base daily. The mechanism of action of both clindamycin and primaquine against Pneumocystis is unknown. The most common adverse reactions with this regimen include skin rash, gastrointestinal complaints, and fever. Primaquine may also cause hemolysis in patients with G6PD deficiency.

\section{Atovaquone}

Atovaquone is hydroxy-1,4-naphthoquinone, an analog of ubiquinone, that was initially developed as an antimalarial agent. It also has activity against P. jirovecii but is less effective than the above regimens. The mechanism of action of atovaquone in infections caused by $P$. jirovecii has not been fully elucidated. However, among Plasmodium species the site of action appears to be the cytochrome $b_{1}$ complex (Complex III). Several metabolic enzymes are linked to the mitochondrial electron transport chain via ubiquinone. Inhibition of electron transport by atovaquone will result in indirect inhibition of these enzymes. The ultimate metabolic effects of such blockade may include inhibition of nucleic acid and ATP synthesis.

Atovaquone is a highly lipophilic compound with low aqueous solubility. The bioavailability of atovaquone is highly dependent on formulation and diet. In suspension it provides an approximately 2-fold increase in bioavailability in the fasting or fed state compared to the previously marketed tablet formulation. Plasma atovaquone concentrations do not increase proportionally with dose.

A randomized, double-blind, controlled trial showed similar rates of successful therapy when comparing atovaquone to TMP-SMX in patients with mild to moderate disease (defined in the study protocol as an alveolar-arterial oxygen gradient $\leq 45 \mathrm{mmHg}$ and partial pressure of oxygen $\geq 60 \mathrm{mmHg}$ measured on room air) and with less adverse events. However, significantly higher 4-week mortality rates and significantly higher rates of no response to therapy were noted in the atovaquone group..$^{50}$ Conditions affecting absorption and thereby decreasing the bioavailability of atovaquone were associated with poorer therapeutic outcomes..$^{50}$ Efficacy has also been shown to be comparable to pentamidine in mild to moderate disease. ${ }^{51}$ The usual dose is in suspension, $750 \mathrm{mg}$ orally twice daily, taken with food to increase its absorption.

Adverse reactions include skin rash, fever, gastrointestinal symptoms, and abnormal liver function tests. Mutations in the cytochrome $b$ gene have been shown to confer resistance to atovaquone.

\section{Pentamidine isethionate}

Pentamidine isethionate is effective therapy for Gambian trypanosomiasis, antimony-resistant leishmaniasis, and P. jirovecii pneumonia. Between 1967 and 1984 its use was restricted to treating infections due to Trypanosoma gambiense and Pneumocystis jirovecii. It then became more commonly used for treatment of PCP among immunocompromised patients before the HIV/AIDS epidemic. The mechanism of action is unclear and may differ for different organisms. Trypanosomes actively transport pentamidine intracellularly, where it may then interfere with DNA biosynthesis. With Pneumocystis pneumonia, pentamidine appears to kill nonreplicating organisms.

There are many studies showing similar efficacy of pentamidine to TMP-SMX, but the former is not favored because of known toxicities and its availability only as an intravenous preparation. ${ }^{52-54}$ Pentamidine is given parentally at $4 \mathrm{mg} / \mathrm{kg}$ once daily and is generally regarded as second-line therapy in severe disease with consideration of its side effect profile. The aerosol route is recommended only for prophylaxis but not for treatment of PCP.

Side effects occur in up to $50 \%$ of patients receiving pentamidine. These reactions have conveniently been categorized as immediate, local, and systemic and have also included deaths. Immediate reactions include hypotension in up to $10 \%$, tachycardia, nausea and/or vomiting, facial flushing, pruritis, unpleasant taste, hallucinations, and syncope. Local reactions of moderate to severe pain at the injection site and less frequently, sterile abscesses and tissue necrosis can occur when given intramuscularly. Urticarial rash, phlebitis and venous thrombosis complicate intravenous administration. Systemic reactions include renal toxicity, electrolyte abnormalities, hypo- and hyperglycemias, cardiac arrhythmias, elevated transaminases and bronchospasm with inhaled treatment.

\section{Trimetrexate}

Trimetrexate is a folinic acid analog structurally related to methotrexate, whose primary mechanism of action is believed to be inhibition of dihydrofolate reductase. This reduces the production of DNA and RNA precursors and leads to cell death. 
Trimetrexate is lipophilic and can passively diffuse across cell membranes including those of Pneumocystis jiroveciii and its mammalian host. To minimise toxicity, trimetrexate must be given with calcium folinate (leucovorin calcium). Leucovorin acts as a reduced folate coenzyme, which is transported into, and protects mammalian host cells, but does not protect target organisms. The recommended dose is $45 \mathrm{mg} / \mathrm{m}^{2}$ once daily, by the intravenous route. Leucovorin is administered every 6 hours at a dose of $20 \mathrm{mg} / \mathrm{m}^{2}$ and should be continued for 72 hours following the last dose of trimetrexate.

The most common adverse effect associated with trimetrexate is myelosuppression (neutropenia and thrombocytopenia) that is generally reversible upon dosage reduction or discontinuation. Other adverse effects include increases in serum aminotransferase, alkaline phosphatase and/or serum creatinine levels, anemia, fever, rash and pruritus. Trimetrexate is an alternative option for patients with moderate to severe PCP who have not responded to or are intolerant of first-line therapy. However, it is no longer available in the US since its production was discontinued in March 2007.

\section{Adjunctive therapy}

In addition to antibiotics, steroids are recommended as adjunctive therapy for moderate to severe PCP (defined as an arterial oxygen pressure of less than $70 \mathrm{mmHg}$ or an alveolar-arterial gradient greater than $35 \mathrm{mmHg}$ ). Ideally, steroids should be given prior to the first dose of any antibiotic or no later than the first 72 hours after the initiation of therapy. ${ }^{55,56}$ The usual "steroid regimen" consists of prednisone $40 \mathrm{mg}$ orally twice daily for the first five days, $40 \mathrm{mg}$ orally daily for another five days, followed by $20 \mathrm{mg}$ orally once daily for an additional 11 days. Methylprednisolone at $75 \%$ of the respective prednisolone dose should be administered if intravenous therapy is necessary. During the first days of therapy adjunctive steroids improve, most importantly, survival, decrease episodes of respiratory decompensation and decrease the need for mechanical ventilation. Steroids likely blunt the inflammatory response (that includes the production of cytokines and other inflammatory markers and cells) to dying organisms that results in lung tissue damage during the early course of therapy. ${ }^{57}$

\section{Future directions and challenges Caspofungin}

Caspofungin is an echinocandin and inhibits fungal beta-1,3glucan synthesis, a main component of the cell wall. It is known to have activity against Candida and Aspergillus species. There is data on its efficacy in cystic forms of PCP in murine models. ${ }^{58}$ Case reports have described its clinical success when used in combination with TMP-SMX in treating PCP in immunocompromised hosts. ${ }^{59-61}$ Though these reports seem promising, clinical trials are needed to support these findings before Caspofungin can be recommended in the treatment of PCP.

\section{Antiretroviral therapy}

Early in the AIDS epidemic, patients with severe PCP and respiratory failure had such high mortality rates that mechanical ventilation and intensive care were not encouraged. There has been a gradual improvement in survival over the last two decades with the adjunctive use of steroids in therapy and improved intensive care management of these patients. ${ }^{62,63}$ This trend can be further enhanced with the early initiation of combination antiretroviral therapy (cART). ${ }^{64}$ The optimal timing for initiation of cART has been a subject of debate. There are well-deserved concerns regarding cART and the possibility of the immune reconstitution and inflammatory response syndrome (IRIS), with paradoxical worsening of PCP and other opportunistic infections (OI). One review of 65 cases of PCP describes an acute worsening of respiratory symptoms in 3 patients after the early introduction of cART. However, they did not report any deaths among these 3 cases. ${ }^{65}$

The first study looking at the use of cART in patients presenting with severe PCP found cART to be an independent predictor of decreased mortality. The mortality among patients not receiving cART was $63 \%$ in contrast to a significantly lower $25 \%$ mortality among patients receiving cART prior to or during hospitalization. ${ }^{66}$ This initial study set the stage for a more recent multicentered randomized trial where early cART was started within 14 days of diagnosis of an OI versus deferred therapy where cART was started after treatment of the OI was completed; usually $\geq 4$ weeks into the study. It was shown that AIDS progression and death were significantly reduced in the early treatment group, especially within the first 6 months of the study. Additionally, for the OIs included within this study of which $63 \%$ where due to PCP, the incidence of IRIS was surprisingly low at $7 \%$. The improved outcome seen with early cART substantiates its consideration in clinical practice along with the fact that patients can usually be supported through an episode of IRIS if it ocurrs. ${ }^{67}$

However, there are some reservations among physicians to the use of early cART. These include non-compliance, loss of follow up post-discharge, drug interactions and the potential for drug toxicities. In regard to critically ill patients especially on hemodynamic supportive therapy, the safety of cART has not been extensively studied. Limitations of poor absorption of orally administered medications, by which 
most antiretrovirals are given, may be erratic, predisposing to resistance and decreased efficacy. Frequent changes in renal and hepatic function can make it difficult to accurately dose medications and the detection of drug adverse effects may be delayed in obtunded patients. ${ }^{68}$ Moreover, to facilitate a smooth transition to out-patient care, access to medications and providers should be in place prior to discharge from hospital.

\section{Challenges in the management of opportunistic infections}

There is a changing approach to the treatment of opportunistic infections, with the accumulating evidence of the early initiation of cART improving morbidity and mortality. Additional clinical trials showing this benefit are needed to develop guidelines on what could become the standard of care. A better understanding of the pathogenesis of IRIS and ongoing studies to help predict those that are susceptible may quell the concerns surrounding early cART, provide more answers and may even lead to improved outcome.

\section{Prevention}

\section{Primary prophylaxis}

Studies have shown that a CD4 count less than 200 cells $/ \mathrm{mm}^{3}$ (or CD4 percentage less than 14) in an HIV-infected patient markedly increases the risk for PCP, and is an indication to start primary prophylaxis. One prospective observational study that supports this recommendation, found $88.9 \%$ of 3101 initial episodes of PCP among an HIV-infected population, had a CD4 count less than 200. ${ }^{69}$ Although PCP is known to occur at higher CD4 counts, the risk is lower, and probably outweighs the potential for a large number of adverse events with prophylactic therapy. Oropharyngeal candidiasis is another indicator for prophylactic therapy, regardless of the CD4 count. Other non-HIV infected patients at risk for PCP include those with hematologic malignancies, solid tumors, inflammatory disorders, as well as bone marrow and solid organ transplant recipients. ${ }^{70}$ For these groups of patients, guidelines on prophylaxis have not been established, but they are considered to be at similar risk as patients with advanced HIV infection. Patients who develop severe PCP while on prophylaxis have a poor outcome and this may be due to acquired co-trimoxazole resistance. ${ }^{71,72}$

TMP-SMX is very effective in preventing PCP opportunistic infections and is the preferred prophylactic regimen. Aerosolized pentamidine is not as effective as bactrim for primary or secondary PCP prophylaxis. ${ }^{73,74}$ However, it is an alternative option for those unable to tolerate TMP-SMZ as stated in the most recent guidelines on the prevention of opportunistic infections in HIV-infected adults and adolescents. ${ }^{75}$ Although aerosolized pentamidine has higher failure rates compared to bactrim, it has been shown that compared to those at risk and not receiving prophylactic therapy, it significantly reduces the incidence of primary episodes of PCP with reasonable tolerance of the inhaled drug. ${ }^{76}$

Atovaquone is another alternative to bactrim for prophylaxis. A study comparing atovaquone to aerosolized pentamidine showed no statistically significant differences between these two drugs with regard to incidence of PCP, death, or the combined end point of PCP and death. ${ }^{77}$ Atovaquone has also been shown to have similar efficacy compared to dapsone, the latter being the second most widely used option for PCP prophylaxis. In a large randomized study among patients with intolerance to bactrim, the rates of PCP pneumonia, survival, and tolerance were similar in the atovaquone and dapsone groups. ${ }^{78}$ The recommended regimens for prophylaxis are listed in Table 4.

Primary prophylaxis may be discontinued once immune reconstitution with CD4 counts $\geq 200$ cells $/ \mathrm{mm}^{3}$ for at least three months occurs with antiretroviral therapy. Nevertheless, it may be possible, to safely discontinue primary prophylaxis for those patients who have failed to show an increase in the CD4 ${ }^{+}$T-cell count above the threshold of 200 cells $/ \mathrm{mm}^{3}$, despite being well controlled on cART, with HIV viral loads $<50$ copies/ml for at least 3 months. It should be noted that the latter is not recommended, but, there is evidence that immune recovery may occur with suppression of HIV alone, even though it is typically thought to be indicated by an increase in the $\mathrm{CD} 4^{+}$T-cell count. ${ }^{79}$ The decreased toxicity and cost with improved adherence to cART would together be of considerable benefit for such patients.

On the other hand, HIV viral loads have not been used to assess the risk for developing PCP and have not been included in guidelines to help determine when to initiate or discontinue prophylaxis.

Prophylactic therapy should be re-introduced if the CD4 count decreases to less than 200 cells $/ \mathrm{mm}^{3}$.

\section{Table 4 Recommended regimens for PCP prophylaxis}

TMP-SMZ one Double Strength tablet once daily or three times a week, or once daily single-strength tablet by mouth (preferred)

Dapsone $100 \mathrm{mg}$ daily

Dapsone $50 \mathrm{mg}$ daily with pyrimethamine $50 \mathrm{mg}$ plus folinic acid $25 \mathrm{mg}$ once weekly

Atovaquone suspension $750 \mathrm{mg}$ twice daily

Aerosolized pentamidine $300 \mathrm{mg}$ every four weeks administered

via Respirgard II ${ }^{\circledR}$ nebulizer 


\section{Secondary prophylaxis}

Patients with a history of PCP should have lifelong chemoprophylaxis, with any of the above mentioned regimens, if immune reconstitution cannot be achieved. If the CD4 count is maintained above 200 cells $/ \mathrm{mm}^{3}$ for at least three months in response to cART, then it may be discontinued. Secondary prophylaxis should be restarted if the CD4 count declines to less than 200 cells $/ \mathrm{mm}^{3}$ or if PCP recurred with CD4 counts above 200 cells $/ \mathrm{mm}^{3} .{ }^{80}$

\section{Conclusion}

PCP is today still one of the most common and most deadly opportunistic infections in patients with Human Immunodeficiency Virus. It is also becoming more prevalent among non-HIV infected individuals as the number of patients undergoing chemotherapy and immunosuppresion after transplant is growing. Clinicians must be familiar with its presentation and management because mild cases are sometimes difficult to diagnose. On the other hand, some severe cases can prove fatal despite full supportive intensive care with mechanical ventilation. Currently, the most effective medication for its prevention and treatment is trimethoprim-sulfamethoxazole but other alternative medications are also available.

\section{Disclosure}

The authors report no conflicts of interest in this work.

\section{References}

1. Center of Disease Control and Prevention. Pneumocystis pneumonia Los Angeles. MMWR. 1981;30: 250-252.

2. Gottlieb MS, Schroff R, Schanker HM, et al. Pneumocystis carinii pneumonia and mucosal candidiasis in previously healthy homosexual men: evidence of a new acquired cellular immunodeficiency. $N$ Engl J Med. 1981;305:1425-1431.

3. The Antiretroviral Therapy Cohort Collaboration (2008) Life expectancy of individuals on combination antiretroviral therapy in highincome countries: a collaborative analysis of 14 cohort studies. Lancet. 2008;372:293-299.

4. Palella FJ Jr, Delaney KM, Moorman AC, et al. Declining morbidity and mortality among patients with advanced human immunodeficiency virus infection. HIV Outpatient Study Investigators. $N$ Engl J Med. 1998;338:853-860.

5. Battegay M, Elzi L. Morbidity and mortality in HIV-infected individuals - a shift towards comorbidities. Swiss Med Wkly. 2009;139:564-570.

6. Chagas C. Nova tripanozomiaze humana: estudo sobre a morfolojia e o evolutivo do Schizotrypanum cruzi n.gen.,sp., ajente etiolojico de nova entidade morbida do homem. Mem Inst Oswaldo Cruz. 1909;1: 159-218.

7. Carinii A. Formas de eschizogonia do Trypanozoma lewisi. Commun Soc Med Sao Paolo. 1910;16:204.

8. Stringer JR, Beard CB, Miller RF, Wakefield AE. A new name (Pneumocystis jirovecii) for Pneumocystis from humans. Emerg Infect Dis. 2002;8:891-896.

9. Edman JC, Kovacs JA, Masur H, et al. Ribosomal RNA sequence shows Pneumocystis carinii to be a member of fungi. Nature. 1988;334: 519-522.
10. Stringer SL, Hudson K, Blasé MA, et al. Sequence from ribosomal RNA of Pneumocystis carinii compared to those of four fungi suggests an ascomycettous affinity. J Protozool. 1989;36:14S-16S.

11. Gigliotti F, Harmsen AG, Wright TW. Characterization of transmission of Pneumocystis jirovecii f. sp. Muris through immunocompetent BALB/c mice. Infect Immun. 2003:71;3852-3856.

12. Chen W, Gigliotti F, Harmsen AG. Latency is not an inevitable outcome of infection with Pneumocystis jirovecii. Infect Immun.1993;61: 5406-5409.

13. Helweg-Larsen J, Lee CH, Jin S. et al. Clinical correlation of variations in the internal transcribed spacer regions of rRNA genes in Pneumocystis jirovecii f. sp. Hominis. AIDS. 2001;15:451-459.

14. Henshaw NG, Carson JL and Collier AM. Ultrastructural observations of Pneumocystis carinii attachment to the lung. J Infect Dis. 1985;151: 181-186.

15. Roths JB and Sidman CL. Both immunity and hyperresponsiveness to Pneumocystis jirovecii result from transfer of CD4+ but not CD8+ $\mathrm{T}$ cells into severe combined immunodeficeincy mice. J Clin Invest. 1992;90:673-690.

16. Wright TW, Johnston CJ, Harmsen AG, Finkelstein JN. Chemokine gene expression uring Pneumocystis-driven pulmonary inflammation. Infect Immun. 1999;67:3452-3460.

17. Gigliotti F and Wright TW. Immunopathogenesis of Pneumocystis jirovecii pneumonia. Expert Rev Mol Med. 2005;7:1-16.

18. Itatani CA, Marshall GJ. Ultrastructural morphology and staining characteristics of Pneumocystis carinii in situ and from bronchioalveolar lavage J Parasitol. 1988;74:700-712.

19. Cruciani M, Marcati P, Malena M, et al. Meta-analysis of diagnostic procedures for Pneumocystis carinii pneumonia in HIV-1 infected patients. Eur Respir J. 2002;20:982.

20. Castro JG, Espinoza L. HIV infection and Pneumocystis Penumonia (PCP). In: Galanda CD, editor. AIDS-related Opportunistic Infections. New York: Nova Biomedical Books; 2009. p. 68-80.

21. Thomas CF Jr, Limper AH. Pneumocystis pneumonia. $N$ Engl J Med. 2004;350:2487-2498.

22. Stover DE, Meduri GU. Pulmonary function tests. Clin Chest Med. 1988;9:473-479.

23. Gruden JF, Huang L, Turner J, et al. High resolution CT in the evaluation of clinically suspected Pneumocystis carinii pneumonia in AIDS patients with normal, equivocal, or nospecific radiograph findings. Am J Roentgenol. 1997;169:967-975.

24. Zaman MK, Wooten OJ, Suprahmanya B, et al. Rapid non-invasive diagnosis of Pneumocystis carinii from induced liquefied sputum. Ann Intern Med. 1988;109-117.

25. Kovacs JA, Ng VL, Masur H, et al. Diagnosis of Pnumocystis carinii pnumonia: improved detection in sputum with use of monoclonal antibodies. N Engl J Med. 1988;318:589-593.

26. Larsen HH, Huang L, Kovacs JA, et al. A prospective, blinded study of quantitative touch-down polymerase chain reaction using oral-wash samples for diagnosis of Pneumocystis pneumonia in HIV-infected patients. J Infect Dis. 2004;189:1679-1683.

27. Desmet S, Van Wijngaerden E, Maertens J, et al. Serum (1-3)-beta-Dglucan as a tool for diagnosis of Pneumocystis jirovecii pneumonia in patients with human immunodeficiency virus infection or hematological malignancy. J Clin Microbio. 2009;47:3871-3874.

28. Shimizu Y, Sunaga N, Dobashi K, et al. Serum markers in interstitial pneumonia with and without Pneumocystis jirovecii colonization: a prospective study. BMC Infect Dis. 2009;9:47

29. Cruciani M, Marcati P, Malena M, et al. Meta-analysis of diagnostic procedures for Pneumocystis carinii pneumonia in HIV-1 infected patients. Eur Respir J. 2002;20:982-989.

30. Harris C, Specter B, Lim W. Unique chest radriograph features of CMV complicating PCP in HIV infected infants. Int Conf AIDS. 1993 Jun 6-11; 9:360. (Abstract N PO-B08-1347)

31. Castro J, Mansi G, Espinoza L, et al. Concurrent PCP and TB Pneumonia in HIV Infected Patients. Scandinavian J Infect Dis. 2007;39: 1054-1058. 
32. Centers for Disease Control and Prevention. Guidelines for Prevention and Treatment of Opportunistic Infections in HIV-Infected Adults and Adolescents, Recommendations from CDC, the National Institutes of Health, and the HIV Medicine Association of the Infectious Diseases Society of America. MMWR. 2009;58:6-10.

33. Hughes WT. Trimethoprim-sulfamethoxazole therapy for Pneumocystis carinii pneumonitis in children. Rev Infect Dis. 1982;4:602-607.

34. Lowell S. Young. Trimethoprim-Sulfamethoxazole in the treatment of adults with pneumonia due to Pneumocystis carinii. Rev Infect Dis. 1982;4:608-613.

35. Hughes W, Feldman S, Chaudhary S, et al. Comparison of pentamidine isethionate and trimethoprim-sulfamethoxazole in the treatment of Pneurnocystis carinii pneumonia. J Pediatr. 1978;92:285-291.

36. Winston DJ, Lau WK, Gale RP, Young LS. Trímethoprimsulfamethoxazole for the treatment of Pneumocystis carinii pneumonia Ann Intern Med. 1980;92:762-769.

37. Sattler FR, Cowan R, Nielsen DM, Ruskin J. Trimethoprimsulfamethoxazole compared with pentamidine for treatment of Pneumocystis carinii pneumonia in the acquired immunodeficiency syndrome. Ann Intern Med. 1988;109:280-287

38. Helweg-Larsen J, Benfield TL, Eugen-Olsen J, et al. Effects of mutations in Pneumocystis carinii dihydropteroate synthase gene on outcome of AIDS-associated P carinii pneumonia. Lancet. 1999;354 1347-1351.

39. Hughes WT, Feldman S, Chaudhary SC, et al. Comparison of pentamidine isethionate and trimethoprim-sulfamethoxazole in the treatment of Pneurnocystis carinii pneumonia. J Pediatr. 1978;92:285-291.

40. Armstrong W, Meshnick S, Kazanjian P. Pneumocystis carinii mutations associated with sulfa and sulfone prophylaxis failures in immunocompromised patients. Microbes Infect. 2000;2:61-67.

41. Safrin S, Finkelstein DM, Feinberg J, et al. Comparison of three regimens for treatment of mild to moderate Pneumocystis carinii pneumonia in patients with AIDS. Ann Intern Med. 1996;124:792-802.

42. Nahimana A, Rabodonirina M, Helweg-Larsen J, et al. Sulfa Resistance and Dihydropteroate Synthase Mutants in Recurrent Pneumocystis carinii Pneumonia. Emerg Infect Dis. 2003;7:864-867.

43. Helweg-Larsen J, Benfield T, Eugen-Olsen J, et al. Effects of mutations in Pneumocystis carinii dihydropteroate synthase gene on outcome of AIDS-associated P carinii pneumonia. Lancet. 1999; 354:1347-1351.

44. Navin T, Beard C, Huang L, et al. Effect of mutations in Pneumocystis carinii dihydropteroate synthase gene on outcome of $P$. carinii pneumonia in patients with HIV-1: a prospective study. Lancet. 2001;358:545-549.

45. Hughes W. Use of dapsone in the prevention and treatment of Pneumocystis carinii pneumonia: a review. Clin Infect Dis. 1998;27: 191-204.

46. Hansen DG, Challoner KR, Smith DE. Dapsone intoxication: two case reports. J Emerg Med. 1994;3:347-351.

47. Landers D, Bergin C, O'Leary A, et al. Dapsone induced methaemoglobinaemia. Int J STD AIDS. 1996;7:445-447.

48. Ward KE, McCarthy MW. Dapsone-induced methemoglobinemia. Ann Pharmacother. 1998;32:549-553.

49. Toma E, Thorne A, Singer J, et al; The CTN-PCP Study Group. Clindamycin with primaquine vs trimethoprim-sulfamethoxazole therapy for mild and moderately severe Pneumocystis carinii pneumonia in patients with AIDS: A multicenter, double-blind, randomized trial (CTN 004). Clin Infect Dis. 1998;27:524-530.

50. Hughes W, Leoung G, Kramer F, et al. Comparison of atovaquone (566C80) with trimethoprim-sulfamethoxazole to treat Pneumocystis carinii pneumonia in patients with AIDS. $N$ Engl J Med. 1993;328: 1521-1527.

51. Dohn MN, Weinberg WG, Torres RA, et al. and the Atovaquone Study Group. Oral atovaquone compared with intravenous pentamidine for Pneumocystis carinii pneumonia in patients with AIDS. Ann Intern Med. 1994;121:174-180.

52. Western KA, Perera Dr, Schultz MG: Pentamidine isethionate in the treatment of Pneumocystis carinii pneumonia, Ann Intern Med. 1970; 73:695-702.
53. Wharton JM, Coleman DL, Wofsy CB, Luce JM, et al. Trimethoprimsulfamethoxazole or pentamidine for Pneumocystis carinii pneumonia in the acquired immunodeficiency syndrome. Ann Intern Med. 1986; 105:37-44

54. Klein NC, Duncanson FP, LenoxTH, etal. Trimethoprim-sulfamethoxazole versus pentamidine for Pneumocystis carinii pneumonia in AIDS patients: results of a large prospective randomized treatment trial. AIDS. 1992;6:301-305.

55. Nielsen TL, Schattenkerk, JKME, Jensen BN, et al. Adjunctive corticosteroid therapy for Pneumocystis carinii pneumonia in AIDS: A randomized European multicenter open label study. AIDS. 1992;5:726-731

56. Montaner JS, Lawson LM, Levitt N, et al. Corticosteroids prevent early deterioration in patients with moderately severe Pneumocystis carinii pneumonia and the acquired immuno-deficiency syndrome (AIDS). Ann Intern Med.1990;113:14-20.

57. Consensus statement on the use of corticosteroids as adjunctive therapy for Pneumocystis pneumonia in the acquired immunodeficiency syndrome. N Engl J Med. 1990;323:1500-1504.

58. Powles MA, Liberator P, Anderson J, et al. Efficacy of MK-991 (L-743,872), a semisynthetic pneumocandin, in murine models of Pneumocystis carinii. Antimicrob Agents Chemo. 1998;42:1985-1989.

59. Annaloro C, Della Volpe A, Usardi P, Lambertenghi DG. Caspofungin treatment of Pneumocystis pneumonia during conditioning for bone marrow transplantation. Eur J Clin Microbiol Infect Dis. 2006;25: 52-54.

60. Xiang-dong M, Cheng-li Q, Bing HE, et al. Caspofungin in salvage treatment of severe pneumocystis pneumonia: case report and literature review. Chin Med J. 2009;122:996-999

61. Utili R, Durante-Mangoni E, Basilico C, et al. Efficacy of caspofungin addition to trimethoprim-sulfamethoxazole treatment for severe Pneumocystis pneumonia in solid organ transplant recipients. Transplantation. 2007;84:685-688.

62. Miller RF, Allen E, Copas A, et al. Improved survival for HIV infected patients with severe Pneumocystis jiroveci pneumonia is independent of highly active antiretroviral therapy. Thorax. 2006;61:716-721.

63. Curtis JR, Yarnold PR, Schwartz DN, et al. Improvements in outcomes of acute respiratory failure for patients with human immunodeficiency virus-related Pneumocystis carinii pneumonia. Am J Resp Crit Care Med. 2000;162:393-398.

64. Morris A, Creasman J, Turner J, et al. Intensive care of human immunodeficiency virus-infected patients during the era of highly antiretroviral therapy. Am J Resp Crit Care Med. 2002;166:262-267.

65. Wislez M, Bergot E, Antoine M, et al. Acute respiratory failure following HAART introduction in patients treated for Pneumocystis carinii pneumonia. Am J Respir Crit Care Med. 2001;164:847-851

66. Morris A., Wachterc R. M., Luce, et al. Improved survival with highly active antiretroviral therapy in HIV-infected patients with severe Pneumocystis carinii pneumonia. AIDS. 2003;17:73-80.

67. Zolopa AR, Andersen J, Komarow L, et al. Early antiretroviral therapy reduces AIDS progression/death in individuals with acute opportunistic infections: A multicenter randomized strategy trial. PLOS ONE. 2009;4:e5575.

68. Huang L, Quartin A, Jones D, Havlir DV. Intensive care of patients with HIV infection. $N$ Engl J Med. 2006;355:173-181.

69. Chu S, Hanson DL, Ciesielski C, Ward JW. Prophylaxis against Pneumocystis jirovecii pneumonia at higher CD4+ T-Cell counts. JAMA. $1995 ; 273: 848$

70. Yale SH, Limper AH. Pneumocystis carinii pneumonia in patients without acquired immunodeficiency syndrome: associated illness and prior corticosteroid therapy. Mayo Clin Proc. 1996;71:5-13.

71. Curtis JR, Yarnold PR, Schwartz DN, et al. Improvements in outcomes of acute respiratory failure for patients with human immunodeficiency virus-related Pneumocystis carinii pneumonia. Am J Resp Crit Care Med. 2000;162:393-398.

72. Crothers K, Beard CB, Turner J, et al. Severity and outcome of HIVassociated Pneumocystis pneumonia containing Pneumocystis jiroveci dihydropteroate Synthase gene mutations. AIDS. 2005;19:801-805. 
73. Schneider MM, Hoepelman AI, Eeftinck Schattenkerk JK, et al. A controlled trial of aerosolized pentamidine or trimethoprimsulfamethoxazole as primary prophylaxis against Pneumocystis carinii pneumonia in patients with human immunodeficiency virus infection. N Engl J Med. 1992;327:1836-1841.

74. Hardy WD, Feinberg J, Finkelstein DM, et al. A controlled trial of trimethoprim-sulfamethoxazole or aerosolized pentamidine for secondary prophylaxis of Pneumocystis carinii pneumonia in patients with the acquired immunodeficiency syndrome. N Engl J Med. 1992;327: 1842-1848.

75. Centers for Disease Control and Prevention. Guidelines for prevention and treatment of opportunistic infections in HIV-infected adults and adolescents. MMWR. 2009;58(No. RR-4).

76. Jensen BN, Nielsen TL, Backer V, et al. Aerosolized pentamidine for primary prophylaxis of Pneumocystis Carinii pneumonia: A controlled, randomized trial. AIDS. 1993;6:472-477.
77. Chan C, Montaner J, Lefebvre EA, et al. Atovaquone suspension compared with aerosolized pentamidine for prevention of Pneumocystis carinii pneumonia in human immunodeficiency virus-infected subjects intolerant of trimethoprim or sulfonamides. J Infect Dis. 1999;180:369-376.

78. El-Sadr WM, Murphy RL, Yurik TM, et al. Atovaquone compared with dapsone for the prevention of Pneumocystis carinii pneumonia in patients with HIV infection who cannot tolerate trimethoprim, sulfonamides, or both. N Engl J Med. 1998;339:1889-1895.

79. D'Egidioa GE, Kravcika S, Coopera CL, et al. Pneumocystis jiroveci pneumonia prophylaxis is not required with a CD4+ T-cell count $<200$ cells/ $\mathrm{ml}$ when viral replication is suppressed. AIDS. 2007,21:1711-1715.

80. Espinoza, LA. Pneumocystis pneumonia. In: Knox MD, editor HIV/ AIDS Primary Care Guide. Williston, VT: Crown House Pub; 2006.
HIV/AIDS - Research and Palliative Care

\section{Publish your work in this journal}

HIV/AIDS - Research and Palliative Care is an international, peerreviewed open-access journal focusing on advances in research in HIV, its clinical progression and management options including antiviral treatment, palliative care and public healthcare policies to control viral spread. The journal welcomes original research, basic science,

\section{Dovepress}

clinical \& epidemiological studies, reviews \& evaluations, expert opinion \& commentary, case reports \& extended reports. The manuscript management system is completely online and includes a very quick and fair peer-review system. Visit http://www.dovepress.com/ testimonials.php to read real quotes from published authors. 